\title{
Intermédialités
}

Histoire et théorie des arts, des lettres et des techniques

Intermediality

History and Theory of the Arts, Literature and Technologies

\section{Logistical Species and Translational Process: A Critique of the Colonial-Imperial Modernity}

\section{Jon Solomon}

Numéro 27, printemps 2016

traduire

translating

URI : https://id.erudit.org/iderudit/1039809ar

DOI : https://doi.org/10.7202/1039809ar

Aller au sommaire du numéro

Éditeur(s)

Revue intermédialités (Presses de l’Université de Montréal)

ISSN

1920-3136 (numérique)

Découvrir la revue

Citer cet article

Solomon, J. (2016). Logistical Species and Translational Process: A Critique of the Colonial-Imperial Modernity. Intermédialités / Intermediality, (27).

https://doi.org/10.7202/1039809ar
Résumé de l'article

Cet article se propose d'esquisser une théorie de la traduction qui nous permettrait de comprendre les liens entre trois types de divisions actives au sein des sociétés modernes : les divisions disciplinaires des sciences humaines, les divisions géopolitiques et géoculturelles des populations mondiales et les divisions économiques du travail, à la fois dans sa relation externe avec le capital et dans le lien entre les différentes formes de travail et la subjectivité. En s'appuyant sur une comparaison entre la théorie de la traduction avancée par Naoki Sakai et la théorie de la transindividuation élaborée par Gilbert Simondon, nous proposons l'idée qu'il existe des relations de type analogique entre ces différentes divisions et que c'est la traduction qui detient la clé pour y accéder. 


\title{
Logistical Species and Translational Process: A Critique of the Colonial- Imperial Modernity
}

\author{
JON SOLOMON
}

T

his essay aims to sketch a theory of translation that would be of use in drawing links among three different types of divisions present in all modern societies: the disciplinary divisions within the institutional organization of scientific and humanistic knowledge, the geocultural/geopolitical divisions among global populations, and the economic divisions of labour, both in its external relation to capital and in the internal relations among different forms of labour to subjectivity. The scale of this elaborate and ambitious project-one sympathetic reviewer even termed it "utopian"-is such that it might be deemed prudent to attack it slowly and obliquely, one piece at a time. While desirable, this approach not only assumes the luxury of time away from the teaching machine that this author does not have, it also crucially introduces an unhelpful element of abstraction that is ultimately part of the bordering process that disciplines, translations, geopolitics, and economy instantiate and negotiate.

Methodologically speaking, my aim is to bring Naoki Sakai's theory of translation into dialogue with Gilbert Simondon's (1924-1989) philosophy of individuation. This sketched dialogue does not attempt to provide an exhaustive account of the possibilities and challenges to such a confrontation, much less offer a global reading of the entirety of each thinker's corpus. Instead, it is surgically focused on a single theme-that of analogy - that is particularly important to translation. Our consideration of the two thinkers does not tarry long before turning summarily to the problem of disciplinary divisions and their relation to a history of labour struggles narrated from the perspective of social communication. 
Before actually engaging this itinerary, I would like to provide advance notice to the reader who will be asked to wade through a potentially confusing series of rapid-fire borrowing and citation seemingly characterized by inexplicable jumps and condensed passages. I find justification for the "jumps" in terms of the analogical method championed by Simondon, but the reality is that my often-clumsy deployment of this methodology may produce undesirable disorientation for the reader. Hopefully, the personal limitations of the author will not eclipse Simondon's brilliant, and admittedly challenging, insight that individuation is a process that occurs across different levels or planes, principal among which would be the epistemological and the ontological. In relation to the theme of translation that binds the concerns of this journal issue, the challenge of analogical parallelism to explain logical "jumps" among discontinuous levels and registers goes to the heart of our understanding of what translation is. Sometimes, it is only through the act of jumping that we are able to realize that what had been previously construed to be a leap across a vast gulf separating one side from the other is in fact the moment when the "sides" are actually constructed or reproduced.

Behind my approach lies, thus, a methodological stance that goes beyond the view of translation as metaphorical, seeing in its tropic dimensions a generalized feature of analogical causality. Besides "jumping," this article will also avail itself of the strategy of "doubling back," repeating the same ideas in different contexts. Hopefully, the ensuing game of intellectual checkers, which is the first game that comes to mind allowing double-back jumps, will be amusing and informative enough to engage the reader's kind attention. This attention will be met by the fruits of a novel idea: As implausible as it may sound, the rather marginal and weak field of translation studies might be viewed as the site of a crucial confrontation not only with the logistical model of bioinformatic capitalism, but also with the way in which that new form of contemporary global domination interdicts communicative possibilities of resistance and liberation by mobilizing ideological elements such as national sovereignty, civilizational difference, and communicational transfer from the apparatus of area and the regime of translation that characterizes the colonialimperial modernity.

I. For a philosophical account of the jump (le saut), please refer to Bernard Aspe, Les mots et les actes, Caen, Éditions Nous, 201 . 


\section{AnAlogy}

In this section, we will prepare for the exciting dialogue between Sakai and Simondon by giving first crack to Simondon, whose work preceded Sakai's by a generation. The key issue on which I would like to focus in this limited space concerns the status of analogy, a crucial problem for theories of translation.

Analogy is commonly understood to be an essential tool of categorization for a simian brain ill-equipped to deal with too much information. Hence, it has played, along with theories of emergence and self-organization, a central role in cybernetics and artificial intelligence ever since Norbert Wiener (1894-1964) and then Warren McCulloch (1898-1969) introduced the idea of an analogous relation between the human brain and computing. Eugene Nida, known as one of the founders of modern translation studies, inaugurates the new discipline, "translation science," with explicit reference to Claude Shannon's cybernetic reduction of communication to message transfer. Despite Shannon's precautions, which limited the scope of his investigation to machine communication, Nida takes the model as an anthropological constant. Given the filiation between cybernetics and translation studies, a critical theory of translation ought to attempt, minimally, to articulate a critique of structuralism to a critique of cybernetics in the context of the apparatus of area. We will initiate that task by putting Sakai's biopolitical theory of translation in conversation with Simondon's critique of the ontological assumptions behind cybernetics.

In order to illustrate the importance of analogy, it is convenient to refer to a review of its place in cognitive science in 2003 by John F. Sowa and Arjun Majumbar, ${ }^{3}$

2. Passages from the present section entitled "Analogy" and the following section entitled "Translation" were first presented in Jon Solomon, "Translation as Analogical Operation (rather than Structural Metaphor)," in Chiara Denti, Lucia Quaquarelli and Licia Reggiani (eds.), mediAzioni, no ${ }_{21}$ "Voci della traduzione/Voix de la traduction," University of Bologna, 2016, http://mediazioni.sitlec.unibo.it/index.php/no-2I-specialissue/Io8articoliarticles-no-2I-20I6-/ 347-translation-as-analogical-operation-rather-than-structuralmetaphor-.html (accessed January 29, 2017). Reproduced (revised and expanded) with permission. I would like to thank the editors of Intermédialités for allowing me the chance to develop these ideas here into an elaborate, unique argument. For more developments on these ideas, in an entirely different context, also see the forthcoming publication, Jon Solomon, "The Affective Multitude: Towards a Transcultural Meaning of Enlightenment," in Steve Choe and Mayumo Inoue (eds.), Beyond Imperial Aesthetics. Theories of Art and Politics in East Asia, Hong Kong, Hong Kong University Press, (forthcoming 2017).

3. John F. Sowa and Arun Majumdar, "Analogical Reasoning," in A. Aldo, W. Lex and B. Ganter(eds.), Conceptual Structures for Knowledge Creation and Communication, Berlin, Springer-Verlag, 2003, p. 16-36. 
who detect a series of three essential propositions at the heart of debates among cognitive scientists concerning the status of analogical reasoning. Sowa and Majumdar adopt a conventional dialectic format, thesis-antithesis-synthesis, to advance-and legitimize before their peers - their argument.

The first stage, qualified as a thesis, considers analogy to be a form of mapping between different structures. Both a cat and a car have a structure, and analogy can map from the cat's eyes to the car's headlights. The "antithesis," or second view in cognitive science, comes from negating the possibility that structure can be separated from mapping (and, one might add, perception from analogy, as I shall explain in a moment). Among cognitive scientists, this point of view has acquired certain acceptance as part of "high-level perception" theories that reject earlier artificial intelligence notions of cognitive representation. The production of analogical associations is not just a module tacked on to perception, but an integral part of perception's order at a higher level. Curiously, Sowa and Majumdar do not consider the discontinuity between mapping and structure, choosing to adhere to the conventional idea of analogy as an identification of similarities between structures. They remain safely within the Kantian privileging of epistemology. Analogy is a response to the epistemological limits of human animal perception, one of the principle ways in which our limited brains create categories that permit action in the face of unforeseen circumstance and change. It is only on the basis of this limitation that we can grasp the ontology of appearance and essence. This notion of analogical thought basically amounts to a theory of associationism, which attempts to explain perception of individual entities rather than undifferentiated continual flux on the basis of experiential analogies that develop through the growth of an individual organism. In the final analysis, associationism is also an implicit, causal theory of cognition.

Perhaps aware that this view of analogical reasoning merely passes the buck down the line, like the "hot potato" of mechanistic causality, ${ }^{4}$ Sowa and Majumdar discern a third view in cognitive science, which they qualify as a "synthesis." This new step is realized by "integrat[ing] the structure-building processes of perception with the structure-mapping processes of analogy." Sowa and Majumdar's "synthesis" relies on the classical assumption that analogy occurs between different structures. In effect, the dialectal form detected by Sowa and Majumbar turns out to be merely formal,

4. Timothy Morton, Realist Magic: Objects, Ontology, Causality, Ann Arbor, Open Humanities Press, 2013, p. 46.

5. Sowa and Majumdar, 2003, p. 17. 
while the terms of the analogical relation posited by cybernetics, and taken up by both artificial intelligence and cognitive science, are based on a premise of identity that does not encounter true alterity, much less indeterminacy.

What happens, we might ask in response to Sowa and Majumdar's account of cognitive science, when we look at analogy, as Simondon does, as a relation between operations rather than structures? Analogy, in that case, would no longer be limited to "structure-mapping processes," but would also occur within "structure-building processes." From this perspective, the integration, or "synthesis" of which Sowa and Majumdar speak, would be transductive, not dialectical.

Simondon understands analogy as an act that puts into relation two operations, while an operation is the conversion of one structure into another. It is this latter conversion that is generally taken to constitute the classic, four-term ( $\mathrm{A}: \mathrm{B}$ is similar to C:D) definition of analogy. This is what Sowa and Majumdar call "the structuremapping process of analogy." Yet for Simondon, this type of conversion, which occurs between structures, is only a "resemblance," rather than an "analogy." ${ }^{6}$ A full-fledged concept of analogy, for Simondon, does not focus exclusively on the identity of elements within a structure, but rather includes the function that relates them. My understanding of Simondon's work relies upon Muriel Combes' relatively early, but still canonical, interpretation: "[S]tructures must be known by the operations that energize them and not the inverse." 7 A structure itself is always part of a processual mutation that Simondon calls, after physics and chemistry, "phasing." 8 Phase shift does not just happen according to properties or characteristics internal to an entity, but rather is the result of a relation between the potentiality of an individual entity to individuate and the metastability of the milieu in which individuation occurs (and "the milieu is not only external to form or structure but also internal to it" 9 ). Hence, analogy signals not just a relation between structures, but also a relation between operations.

The reason why Simondon looks at operations in addition to structures is because of a critical understanding of the limits of the structural model for science. The challenge is that while structure easily lends itself to being an object of positive

6. Gilbert Simondon, L'individuation à la lumière des notions de forme et d'information, Grenoble, Éditions Jérôme Millon, 2013, p. 533.

7. Muriel Combes, Gilbert Simondon and the Philosophy of the Transindividual, translated by Thomas LaMarre, Cambridge and London, MIT Press, 20I3, p. го.

8. Simondon, 2013, p. 25.

9. Combes, 2013., p. 87. 
knowledge, operation can only be known by the discontinuities it negotiates. Simondon thus develops an explanation of analogical acts that are based on the "themes of non-deterministic causality and of non-substantial identity." "'o What this allows Simondon to do is to establish a parallel relation between thought and being such that each operates according to the same paradigm of individuation through transductive relation. "Analogical knowledge thus establishes a relation between the operations of individuals existing outside thought and the operations of thought itself." "I This kind of knowledge enables a means to conceptualize the passage from one domain of being to another "by the transfer of operations from one structure to another." ${ }^{12}$ The strict parallelism established here also means that no entity is privileged over any other as a vantage point from which to understand existence. Thomas LaMarre, Combes' English translator, explains: “And so, in styling both organisms and mechanisms as 'objects,' [Simondon] reminds us that these beings or modes of existence are ontologically different in degree (analogous), not ontologically different in kind or nature (substantially)." "13 On the basis of these two parallel aspects-between epistemological individuation and ontological individuation on the one hand and between organisms and mechanisms on the other-we can say that the analogical act enjoys a status that is not just epistemological, but also ontological. Yet it is not an act that could be attributed to anything other than the entities themselves, each and every instance in their singularity.

\section{TRANSLATION}

Now that Simondon has been given a good warm-up, let us introduce Sakai into the ring. Once again, my aim in this essay is not to provide an exhaustive account of Sakai's theory of translation, but to prepare a dialogue sketch, which we can then take on tour to perform in other fields. The main plotline of the sketch revolves around a transposition of Sakai's theory of translation into Simondonian terms, to effect, as it were, an analogical translation.

Io. Andrea Bardin, Epistemology and Political Philosophy in Gilbert Simondon: Individuation, Technics, Social Systems. Dordecht, Springer, 20I5, p. 8.

II. Combes, 2013, p. Io.

I2. Ibid., p. I4.

13. Thomas LaMarre, "Afterword: Humans and Machines," in Muriel Combes (ed.), translated by Thomas LaMarre, Gilbert Simondon and the Philosophy of the Transindividual, Cambridge and London, MIT Press, 2013, p. 90. 
The connections that I am drawing here require us to distinguish between a metaphorical understanding of translation and an analogical one. Timothy Morton writes, "metaphor is just Greek for translation, since meta means across and -phor means carrying." I4 In Sakai's theory of translation, this is the epistemologicalrepresentationalist view of translation against which he advances a temporal-practical view. The distinction between the two enables Sakai to show how translation or, really, the representational regime of translation, rather than the actual practice of translation, is mobilized by the modern nation-state to configure itself in relation to an international cartography of areas. Within this cartography, the modern regime of translation maps out social relations according to the territorial metaphors of transfer and filtering. At the heart of this schema of internationalism lies an idealist reduction of translation to representation. For Sakai, the crux of this reduction occurs in the loss of the originary foreignness, or discontinuity in the social, which calls for a translation under a representational regime. Instead, Sakai calls for a recognition of the essentially hybrid nature of modern subjectivity seen most clearly in the position of the translator. Described as a "subject in transit," the translator is not a mediator between two discrete language-people communities, but rather a guardian of discontinuity in the social that destroys the presuppositions of homolingual address even in situations where everybody speaks "the same language." The stewardship of discontinuity conferred upon the translator is seen in the care accorded by Sakai's theory of translation to the moment of address.

Morton asserts that translation is an implicit theory of causality: "Causality is much better thought as translation." Is This is not a linear process, but reticulative and transductive. "When an iron bar clangs to the floor of a warehouse, it retroactively posits the warehouse flow in a certain way. That's what translation is." ${ }^{16}$ The notion of retroactivity is essential to Sakai's critique of the epistemological representation of translation:

Only retrospectively and after translation, therefore, can we recognize the initial incommensurability as a gap, crevice, or border between fully constituted entities, spheres, or domains. But when represented as a gap, crevice or border, it is no longer incommensurate $[. .$.$] incommensurability or difference is more like "feeling" that is$ prior to the explanation of how incommensurability is given rise to and cannot be

\footnotetext{
I4. Morton, 2013, p. 70.

I5. Ibid., p. 83 .

16. Ibid., p. 145 .
} 
determined as a represented difference (or species difference in the arborescent schemata of the species and the genus) between two subjects or entities. ${ }^{17}$ systematically defined entities that pre-exist the translational situation transforms incommensurability and discontinuity into a representational form of the commensurable and the continuous. In this sense, the epistemological representation of translation posits an implicit theory of causality that is basically universal..$^{18} \mathrm{It}$ is not the incommensurability between/within languages that calls forth the need for translation, but rather the structural equivalence between two discrete unities. Discrete entities linked by contiguous causality constitute the implicit paradox of the epistemological representation of translation.

An analogical understanding of translation à la Simondon would look at it not as a transferential correspondence between two structures, but as a relation between two operations each of which is related to the transformation of structure. It will be noticed, of course, that what I have been calling the epistemological representation of translation essentially adopts the analogical form that Simondon calls "resemblance" as opposed to "analogy." Resemblance, as noted above, exclusively concerns the metaphorical and metonymical relation between structures. In the case of translation, this would be the structuralist view of language as a system constituted prior to its deployment that excludes speech (parole) from consideration. Against this truncated understanding of resemblance (which Simondon associates with early cybernetic theories of information exchange), the analogical perspective promoted by Simondon takes into account not just structures, but also operations (the latter meaning "relational processes").

The importance of the attention that Simondon devotes to operation, or relational process, in conjunction with structure, is reflected in the way in which Combes begins her seminal work on Simondon. The first chapter, which aims at what is termed "the reality of relation," opens with a section titled "The Operation." In this section, she explains how atomism and hylomorphism constitute, for Simondon, the primary ontological errors of previous philosophy, which equates being with the

17. Naoki Sakai, Translation and Subjectivity: On "Japan" and Cultural Nationalism, Minneapolis, University of Minnesota Press, 1997, p. I4.

I8. For a discussion of causality in relation to translation see Kaisa Koskinen, "Agency and causality: Towards explaining by mechanisms in translation studies," in Tuija Kinnuunen and Kaisa Koskinen (eds.). Translators' Agency, Tampere, Tampere University Press, 2010, p. 165-187. 
givenness of the individual. "[I]n privileging the constituted term, [traditional ontology] has ignored the operation constituting the individual, that is, individuation as process.” I9 I do not have time here to explore fully Simondon's solution to the ontological and epistemological problems called forth by the introduction of operation into structure, but clearly the aim is to develop a science of discontinuous processes that preserves discontinuity without turning it into the commensurable. Andrea Bardin summarizes: “[W] hat Simondon calls 'operation' is-in evident consonance with a Bergsonian matrix - an actual process, inaccessible as such to objective knowledge." 20

With regard to Sakai's theory of translation, a point of conjuncture with Simondon's notion of operation can be seen in Sakai's understanding of the position of the translator. If, as Combes claims, "being can be adequately known only from its middle, by seizing it at its center (by way of the operation of individuation and not on the basis of the term of this operation)," ${ }_{21}$ then it makes perfect sense to examine the role of the translator situated between the two audiences for whom translation is necessary. Yet as Sakai observes at the beginning of his discussion of the position of the translator:

As long as the position of the translator is set aside and viewed to be secondary [with regard to linguistic practice in general], [...] two different language communities [will inevitably be] posited as separate from one another in the representation of translation, and $[. .$.$] translation [will be] understood to be a transfer of a message from one clearly$ circumscribed language community into another distinctively enclosed language community. ${ }^{22}$

The way in which Sakai overcomes this problem hinges upon distinguishing a moment that is distinct from the structure of communicational transfer. The name for this moment is address. ${ }^{23}$ As a performative moment, address names the instantiation of a relation (between addressor and addressee) that occurs prior to, and without any guarantee of, the informational exchange that characterizes communication. To summarize, address thus names an operation in the Simondonian sense, "inaccessible as such to objective knowledge," to be judged rather by its performative, individuating effects.

\footnotetext{
19. Combes, 2013, p. 2.

20. Bardin, 20I5, p. 7 .

2I. Combes, 2013, p. 2-3.

22. Sakai, 1997, p. 5-6.

23. Ibid., p. 4 .
} 


\section{A Critique of Area Studies ${ }^{24}$}

Despite the logical, or rather ana-logical, connections, between the bifurcated aspect of my approach, the choice of texts, authors, ideas, and situations remains occasionally contingent and aleatory. There is, thus, a need to contextualize those choices, which are inevitably contingent rather than logical (as often because of my own limitations as because of illustrative clarity). The first part of the bifurcation that concerns our inquiry into translation deals with the problem of cultural individuation that could be summarized by the question: "What form of social organization constitutes the basic unit of cultural 'identity' in the modern world?" The simple answer to this question is that, through the colonial encounter, ${ }^{25}$ which constituted the anthropological experience of modernity, the basic normative "unit" of cultural individuation has come to be equated with nation-state sovereignty. At the heart of this normative unit lies an identification of language and people as determinate entities; between these two entities (language and people), a relation of necessary, rather than contingent, equivalence is presupposed. The nation-state combines this identification of language and people (the nation) with a state form. In the economy of necessity enabled by the identification of language and people, the state is primarily concerned with representation, both in the dual sense of speaking for the cultural unit in dealings with other sovereign cultural units and with depicting it faithfully. Hence, our inquiry necessarily concerns the limits of a theory of representation for the understanding of cultural individuation. Here is where Sakai's heterolingual theory of

24. Several passages in this section appeared in a prospectus co-authored with Naoki Sakai for the 2016 workshop of the Flying University of the Transnational Humanities. They have been modified for incorporation into this article with agreement from Naoki Sakai. This material was added in response to comments from blind reviewers desirous of greater contextualization for the arguments about translation and labor. I am grateful both to those reviewers for their comments and to the editorial committee of Intermédialités for allowing me space for extensive additional material. Jon Solomon and Naoki Sakai, "Prospectus. The Future of the Humanities and Anthropological Difference: Beyond the Modern Regime of Translation,” Cornell University, July IO-I4, 2016, http://eap.einaudi.cornell.edu/sites/eap/files/ FUTH_prospectus_final.pdf (accessed January 8, 2017).

25. Antony Anghie, Imperialism, Sovereignty and the Making of International Law, Cambridge, Cambridge University Press, 2004, p. 3. 
translation, which hinges on a distinction relevant to representation, is particularly pertinent. Discerning between an epistemological, representational understanding of translation-one that creates the image, or figure, of discrete language-people unities-and a practico-temporal aspect of translation-one that reveals social relations as ongoing processes of fundamentally indeterminate (or plastic) individuation-Sakai's theory of translation offers an integral explanation of the limits of the modern regime of representation. ${ }^{26}$

Take for example the notion of fidelity that previously dominated translation studies. In effect, fidelity amalgamates the two forms of representation in the sense that a translation adhering to the principle of fidelity should speak in place of the foreign other while presenting a lovingly faithful depiction of that foreign other for the target audience. Such representational notions of translation are behind Roman Jakobson's famous claims that translation should be seen as an operation external to the norms of quotidian linguistic practice, thus classifying it as exceptional, secondary and derivative. ${ }^{27}$ Needless to say, norms are not self-grounding, but rather act in the mode of representation, retroactively justifying the positivity of the given. Sakai's theory of translation begins instead with the discovery that translation names something essential about the indeterminacy inherent in all forms of linguistic practice, and aids us in realizing that the problem of representation is continually displaced towards a more fundamental and quotidian level, translational practice.

The second part of the bifurcation arising out of our point of departure is related to the disciplinary divisions of the humanities. My interest in disciplinary

26. Having published a series of articles about Sakai, I would ask the reader to consult the following texts for further details: Jon Solomon, "Translation, Violence and the Heterolingual Intimacy," in "Translating Violence," Transversal, European Institute for Progressive Cultural Policies, $\mathrm{n}^{\mathrm{O}}$ II, fall 2007, http://eipcp.net/transversal/IIO7 (accessed January 4, 2017); Jon Solomon, "Rethinking the Meaning of Regions: Translation and Catastrophe," translate. Beyond Culture: The Politics of Translation (research project), European Institute for Progressive Cultural Policies, 2008, http://translate.eipcp.net/transversal/o6o8/solomon/en (accessed January 14, 2017), also published in German: "Die Bedeutung der Regionen überdenken. Übersetzung und Katastrophe,” in Stefan Nowotny(ed.), Borders, Nations, Translations Übersetzung in einer globalisierten Welt, Vienna, Verlag Turia + Kant, 2008, p. 165178; Jon Solomon, "Transition to a world society: Naoki Sakai's work in the context of capitalimperialism," in Richard Calichman and John Namjun Kim(eds.), The Politics of Culture: Around the Work of Naoki Sakai, New York and London, Routledge, 2010, p. 138-156; Jon Solomon, "The Postimperial Etiquette and the Affective Structure of Area," Translation, no 4 , 20I4, p. I7I-20I.

27. Roman Jakobson, "On Linguistic Aspects of Translation," in Brower, Reuben Arthur (eds.), On Translation, Cambridge, Harvard University Press, p. 232-239. 
divisions focuses not on the differences among disciplines that occur in terms of methods, objects, and theses, but rather on the historicity of the humanities. From this perspective, the development of the humanities, the emergence of new disciplines and their subsequent evolution, can be broadly understood as a historical trajectory. What we are calling the bistorical trajectory of the bumanities is not just another attempt to argue for the importance of power relations in the production of knowledge, but rather a way to grasp the history of translation and translation as history. In order to describe the crucial yet unthematized role played by translation in disciplinary divisions, and thus to illustrate why a critique of the postcolonial divisions of either populations or knowledge will necessarily have to involve a simultaneous foray into both sides of the equation, it will be useful to underline the specific institutional locus in which they arose, both in Sakai's own pioneering work, and in my various attempts over the past two decades to mobilize Sakai's ideas about translation, disciplinary critique, and the historical legacy of colonial-imperial modernity around the theme of biopolitics. This locus is what is typically called in North America "area studies."

First, a word about area. Unlike the notion of territory, which is closely affiliated with population and state sovereignty in the modern international world, the area is essentially an apparatus. It operates through a multiplicity of practices to capture, regulate, manage, and reign the "interaction," or productive relationships, between a given population and a given territory within a capitalist regime of accumulation. While such interactions would be easily and immediately associated, especially in Marxist theory, with the material aspects of production, it is essential to underline the equally important and prodigious role played by the production of subjectivity. The apparatus of area can be distinguished from territoriality precisely in terms of its subjective effects. Hence, we might venture the following formula: while identity and politics would be most easily associated with territory and the state, subjectivity and biopolitics would be a more appropriate conceptual association for area.

Subjectivity, as has been argued since Kant, is primarily concerned with the role of knowledge. Kant's critical project begins with an inquiry into the conditions of possibility for knowledge. Although theories of subjectivity since the $19^{\text {th }}$ century have emphasized the role of other factors, such as the subconscious, material conditions, and affect, knowledge remains a crucial element for understanding modern subjectivity. In relation to the apparatus of area, the easiest place in the institutional production of knowledge to apprehend this connection undoubtedly would be area studies. Typically, the region or populace targeted by area studies is a remote or exotic object of concern. Unlike the territory that defines the extent of sovereignty for the sovereign 
state in the system of international law, the area is a colonial apparatus, an extension of governmentality beyond the confines of sovereignty. ${ }^{28}$ Knowledge production forms an integral part of this polyvalent apparatus. Historically speaking, the "fields" that composed area studies consisted of an interdisciplinary arrangement in which both normative human sciences and regional and local knowledge were mobilized to produce knowledge on areas. The salient feature of knowledge production in the area studies format was not only to reproduce political legitimacy for (neo)colonial discursivity and provide policy for colonial-type governmentality, but first and foremost to fashion subjectivity in relation to a process of bordering. Area studies, in other words, surreptitiously assumes, in an inverted form, the task that one would normally assign to studies of national aesthetics and tradition.

This is one reason why, despite repeated attempts, the model of area studies has been applied only to regions outside the north Atlantic-sometimes called the Westin this case, namely, Western Europe and North America. While I do not have time here to rehearse a comprehensive history of the institutionalization of area as an apparatus of colonial governmentality, an illustration from the history of the United States could be useful. In the case of the United States, area is a notion specific to the post-World War II era of Pax Americana, which exercised global hegemony on the basis of postcolonial sovereignty that both retained colonial governmentality under erasure and reflected a new synthesis of the principle of territoriality and colonial governmentality. However, it is important to keep in mind that the principle of territoriality, which represents the integral unity of the nation-state sovereignty, was not totally discarded. Consequently, the national disciplines organized under the general rule of territoriality - national history, national literature, and so forth-in the "outside" countries, i.e., the so-called "Rest" that lies outside "the West"-were

28. Eventually, this distinction would have to be adjusted to account for the forms of colonization that are internal to the modern nation-state. In that sense, territory might be defined as the way area looks when viewed through the ideological lens of state sovereignty, where the word "ideological" is understood in a strictly terminological sense referring to relations of production, and the word "state" refers to a state-of-class. Needless to say, to recognize a moment of internal colonization, which makes colonization a general problematic of the nationstate, is not to deny the conditions of modernity's differential and hierarchical institutionalization based on a multidimensional distinction between external colonization and internal imperialism. In any case, the essential coloniality of the modern state's appropriation, or representation, of the productive relation or interaction between people and territory is what is at stake, including the production of subjectivity as well as the production of finished goods and surplus value. 
invariably involved in a peculiar complicity with the disciplines of area studies in the United States.

Since the $18^{\text {th }}$ century, some notable disciplines such as national history, national literature, and historical linguistics have been constituted in order to cultivate national subjectivity for nation-states. These disciplines have indeed been framed within the notion of national territory, but in fact equally form what we would call an apparatus of area. In the formation of the state and its subject population, each of the nation-states tried to create in roughly similar fashion its national history, literature, language, and so forth, even though the development of these institutions did not necessarily follow the same chronology. Accompanying the formation of the territorial national state sovereignty was the invention of the national language as the basic medium in which academic conversation was conducted. The core project in the production of national subjectivity was the formation of protocols and institutions of national translation. All humanistic knowledge had to be translated into the terms of national institutions, including national language and the various disciplines of knowledge that rely on it, to be recognized as such. Prior to the establishment of modern human sciences, academic knowledge was expressed and conserved in such classical languages as Latin, Sanskrit, Arabic, and Classical Chinese, each of which was independent of a particular nation, ethnicity, or national territory. Of course, local languages were often used in pedagogy, correspondence, and debates in academia, but the authorized form of academic knowledge was most often sought in those universal, cosmopolitan languages that were seen as the exclusive media for the Truth. And knowledge not expressed in these universal languages was rarely granted the status of authentic and eternal verity.

From the outset of the Reformation in Western Europe, however, the relationship between the classical universal languages and the local, particular ones has undergone radical changes. What we refer to as "the modern regime of translation" played the decisive role in forming the new configuration of national languages on which the development of human sciences has been dependent. In the $18^{\text {th }}$ century, a new type of state sovereignty-territorial national sovereignty-emerged in North America and Western Europe, and a new style of polity, the nation-state, and an equally new kind of community, the nation, came into existence. Modern universities were indeed conditioned by the results of these historical vicissitudes, and modern human sciences or the disciplines of the humanities have been involved in the task of producing national subjectivity in accordance with national languages. In order to 
understand the humanities as a historical trajectory, therefore, it is impossible to overlook the significant role played by the modern regime of translation.

This regime of translation, exemplified by the complicity that I have described between area studies and national disciplines, could be extended further to include those normative disciplines, such as philosophy, anthropology, or sociology, that are not directly concerned with the archive of national tradition and the development of national aesthetics, but rather purportedly deal with the aspects of universal humanity such as the faculty of reason, kinship structures, modes of exchange, etc. In their normativity, these disciplines are part of the implicit, anthropological project that complements the explicit, political project (a.k.a. the Enlightenment), appropriated by the normative unit of the nation-state. What I denote by the term "anthropological project" is a vast compendium of knowledge production that attempts to "figure out" an anthropological image. Throughout the colonial-imperial modernity, this project has been plotted along two axes. One attempts to describe anthropological speciesbeing in relation to its primary Others, the animal and the machine. The other attempts to develop an exhaustive cartography of the human by mapping the empirical and transcendental forms of social organization. The empirical forms concern the totality of human societies that have existed since a supposedly unitary, paleo-anthropological origin; the transcendental forms concern the essential structures of anthropological sociality.

The apparatus of area is distinguished from the notion of territoriality precisely by cross-mapping from territory to anthropological types, both of which are constituent elements in the subjectivity produced by the apparatus. The disciplines for modern knowledge production on human nature-generally referred to as the humanities or human sciences-have been accommodated within the historically specific, bipolar structure that consists of two orientations. Subsumed under the first orientation are the group of normative sciences without geopolitical modifiers, disciplinary forms of knowledge production, such as psychology and philosophy, on what has been regarded as bumanitas or human beings in general. Subsumed under the second are particular disciplines of knowledge production on what have been seen as anthropos or human beings in their specificity, whose particularity is marked by geopolitical adjectivals such as Indian and Chinese in Indian and Chinese philosophies. It is widely believed that those names of normative sciences without modifiers have been handed over from the European tradition, and that they developed as the disciplinary forms of knowledge, as universities transformed themselves into modern educational and disciplinary institutions for the modern territorial and national 
sovereignties within Europe. The assumed universality of bumanitas and its normative status have been endorsed within the framework of the modern national state. In contrast, human sciences for antbropos have dealt with human natures in their regional, cultural, or historical specificities, and with exotic knowledge as Europe expanded and came across strange peoples and places. In other words, the humanistic sciences on anthropos are supposed to cover Europe's encounter with its others, with the rest of the world. To the extent that Europe assumes the position of centrality, European humanity serves as the standard for knowledge production, as the norm for the humanities. It has been assumed, therefore, that human sciences on bumanitas must be given a normative status and their knowledge be deployed in the modality of universality, whereas human (and social) sciences on antbropos must be given a derivative status with their knowledge in the modality of particularity.

These two distinct orientations in humanistic knowledge have been based upon the presumed anthropological difference, thanks to which one unique type of life attitude - that has been characterized as the spiritual shape of European or Western humanity - is distinguished from the other types to be found in the remaining global humanities. The anthropological difference associated with different orientations to humanistic knowledge is based on an implicit hierarchy. While knowledge produced in the mode of humanitas claims correspondence with the fabric of reality, that which is produced in the mode of anthropos can only claim correspondence with a limited field of experience that has not yet been elevated to the status of universal knowledge. In order to remove the limitations imposed by a particular field of experience, a process metaphorically likened to that of filtering is required. ${ }^{29}$ This process of filtering occurs in direct proportion to the amount of particularistic "filtering," due to the cultural limitation, inherent to antbropos. Hence, knowledge produced by and about anthropos always requires translation, a process of filtering that would eliminate particularistic residue, before it can accede to the status of knowledge produced in the mode of bumanitas.

Although this essay does not include a critical elaboration of the anthropological project among its goals, the mere citation of this project, as a research hypothesis, is pertinent to our understanding of the extent to which the modern regime of translation governs knowledge production through the modes of address "hard-wired" into the institutional configuration of disciplinary divisions. The

29. See Naoki Sakai, "Translation as a filter," Gavin Walker and Naoki Sakai (tr.), Transeuropéenes, March 25, 20I0, http://www.transeuropeennes.eu/en/articles/200/ Translation_as_a_filter (accessed January I4, 20I7). 
nationalization of language at the basis of the modern university system in nationstates around the world constitutes an implicit discipline of address within an international regime of translation. The community, or "nation," that was used by states to justify the creation of a linguistic tool for market unification and governmentality is an entirely new social formation, in which the principle of kinship affiliation has played only a restricted role in creating the sense of individual identity. The nation introduced an entirely different form of individual identification and camaraderie, and a strict distinction of insiders from outsiders of the national community of sympathy. The nation is unprecedented as a social formation because what constitutes the bonds of collective attachment among its members is an aesthetic construct, described, in a representative moment for British Liberalism, as "the sentiment of nationality" by John Stuart Mill..$^{\circ}$ Corresponding to this sentiment of nationality is the idea of the national language, which supposedly inheres in every native member of the nation, and is imminent in the feeling of its collective identity. Nationalism holds that the national language can be traced back to a prehistoric origin. But, of course, this is a fiction that helps sustain the reality of the nation as a fictive ethnicity.

Despite the myth of its origin, however, the national language itself is always a product of internationality, of a comparative procedure by which one language is posited as external to another. It does not derive from the past of the remote origin. Rather it is constituted in relation to another language, through what Sakai has elsewhere called the schematism of co-figuration. All the modern national languages, English, German, French, Japanese, Chinese, and so on, were formed through the modern regime of translation at the demise of the authority associated with classical universal languages. Ever since the birth of the modern university in the $8^{\text {th }}$ century in Europe, the disciplines in the humanities have been organized with a view to the production of national subjectivity, as what I have called "the subjective technology of national translation.”

Yet rather than attack the regime of translation constructed upon homolingual modes of address through the avenue of the normative or national disciplines, I propose that it will be much more efficient to privilege area studies. Here we find an easily recognizable site of intervention into the configuration that sustains not just the distribution of the universal and particular modes of address that constitute the unity

30. The term is used by Mill in his treatise on democracy, John Stuart Mill, Considerations on Representative Government, London, Parker, Son, and Bourn, I86I, particularly in Chapter I6, "Of Nationality, as Connected with Representative Government." 
of the modern humanities, but also the geocultural and geopolitical unity of the normative, nation-state "units" that constitute the modern system of internationality. In general, it is assumed that some form of relation or correspondence exists between the realities of cultural individuation "in the world" and disciplinary specialization "in the university." This correspondence generally takes the positivity of the given, the normative unit of cultural individuation, as its point of departure. Since there is a sovereign geocultural unit of Chinese, so the reasoning goes, there ought naturally to be a field of research-say, China studies-devoted to the humanistic objects associated with that unit, all of which can be summarily described as "Chinese," organized into a "field." Area studies, according to this idea, would be called forth by the positivity of objects given in the social world.

The discipline of address institutionally intrinsic to the constitution of area studies presents a key point of access beyond the positivity of its given objects, reminding us of the essentially social nature of knowledge production. As described by Sakai in his theory of translation, the moment of address is a non-objectivizable event, the "taking-place" (as both event and spatial localization) of ontological relationality through which individuation occurs and reoccurs. The moment of address indicates an indeterminacy of position that becomes especially visible in the position of the translator, yet characterizes linguistic communication in general. This moment of indeterminacy leads Sakai to distinguish a mode of address that is fundamentally heterolingual, opposed to another one that is fundamentally bomolingual. The difference between the two does not concern the number of languages, but rather the way in which language is perceived to be bordered, defined, or individuated. For the area studies, this individuation is invariably linked to the specter of anthropological difference that distinguishes those social objects considered to be legitimately part of the disciplinary field and those that are not. The moment of address institutionalized in area studies is precisely the place where individuation at the geocultural level meets individuation at the epistemologico-disciplinary one, or again, where the individuation unleashed in translation meets the individuation codified by disciplinary divisions as much as nation-states.

The moment of address suggests a novel way to understand disciplinary divisions in the humanities. What is unique about area studies is that scholars, regardless of ethnic origin, in those fields, unlike scholars engaged in the theoretical and normative disciplines of the humanities, must always directly confront the process of knowledge production in their field as a social relation enjoined with the peoples, cultures, and languages that serve as their object. What is crucial to the operation of 
this system is the way in which the moment of address is intrinsically tied to a spatially bounded apparatus through which subjectivity is produced. Historically speaking, area studies as a form-of-address was implicitly directed at an idealized audience-the educated, non-specialist Western reader-associated with the nationalized linguistic community of the imperial nation, while always having to account for its role in addressing, even if only obliquely, an actual audience of "natives" in the "area." Even as area studies, unlike the normative humanistic sciences, always had to confront a relation to the Other in the production of knowledge, this confrontation was invariably mediated by the unilateral nature of the disciplinary form of address. Area studies implicitly assumed that its primary audience was unaware of local, empirical particularities as it simultaneously spoke about, hence inevitably to, those Others. Area studies thus offered an empirical contribution to the transcendental universality of the anthropological project as a whole. The confrontation in knowledge production with social relations mediated by the regime of translation in the mode of homolingual address is undoubtedly the single greatest reason why area studies symptomatically reveals the translational relations coded in the disciplinary divisions of the humanities as a whole.

In that sense, area studies are truly faithful to the early cybernetic model of translation that sees it as transfer, even as communication studies abandoned this model long ago. Here again we might detect the difference in terms of institutionally codified modes of address. The political meaning of a rejection of the transferential model of translation by discipline that is not intrinsically obliged to recognize in its production of knowledge a relation to the colonial Other-such as we might find in contemporary communication studies, where the early cybernetic model has been discredited-is wholly different from what it would be were the same gesture to be enacted in a discipline inescapably bound to such recognition, such as area studies. This general example illustrates a logistical aspect inherent in the relation between area studies and normative disciplines. While area studies export data about empirical social formations, they invariably (and selectively) import "theory" from normative disciplines in circulation of unequal flows and distributed heterogeneity. Hence, the modern regime of translation seen from the perspective of area studies includes both a crude cybernetic model of transfer and a flow-chart of logistical operations.

The modern regime of translation, revealed by area studies, would best be characterized as an integral part of an apparatus for logistically managing the production of subjectivity according to a differential cartography of modes of address codified into representations of anthropologically coded areas. One of the enduring contributions 
of Sakai's innovative approach to translation has been to show how the representation of translation as a transfer-across-the-frontier between ostensibly commensurate linguistico-cultural spheres has been crucial to the establishment of modern national subjectivity. Sakai's deconstruction of the theoretical basis of nationalized schemes of translation contains an implicit critique of cultural individuation. Under the modern regime of translation, the essential hybridity and indeterminacy of language and people revealed by the occasion of translation is reduced to a structural correspondence that permits the identification of discrete linguistico-cultural unities between which transfer occurs. This is what might literally be called a metaphorical understanding of translation. In Sakai's theory of translation, instead of a transferential correspondence between two structures, we find operations and events that modify structure, yet cannot themselves be reduced to structure. This is exactly the sort of relationship that Simondon characterizes as analogical.

Our comparison between Sakai and Simondon-or rather, an analogical translation between the two-gives cause to revisit the cybernetic, logistical model that remains even today the implicit paradigm for area studies. The goal is to deepen our understanding of what it means to "uphold the idea," at the heart of transmedial studies as described by one its founders, Éric Méchoulan, "that the relation is in principle primary." ${ }^{\mathrm{I}}$ To begin, in other words, from relation, not the terms that constitute the relation. In terms of the common metaphor of translation as a bridge, this means turning the common wisdom on its head, to the point at which we can see how the "bridge" constitutes the "banks" it supposedly traverses, or again, to restate the metaphor described above, the point at which the "jump" between "banks" allows us to see how the "banks" are formed.

\section{LOGISTICAL MODELS}

In the second half of this essay, I would like to sketch out a line of attack that leads from a theory of translation as transindividuation to an intervention into the disciplinary formation of knowledge under capitalist regimes of accumulation. The telescopic nature of this argument will find justification, I hope, in relation to transmediality by focusing particularly on the role of labour and the zone of indiscernibility between the material and the immaterial.

3I. Éric Méchoulan, “Intermédialités: Le temps des illusions perdues," Intermédialités, no I, 2003, p. II. 
Bardin relates the asymmetry of structure and operation to a history of disciplinary formation: serving as the main object of scientific inquiry since the $17^{\text {th }}$ century, a replacement of structure by operation only becomes possible within the arrangement of the modern institutions of knowledge with the transition to quantum physics in the $2 \mathrm{O}^{\text {th }}$ century..$^{32}$ Bardin's observations serve as a pertinent reminder of the practical need for a critical history of translation in the formation of the disciplinary divisions of the human sciences as they were born out of and bequeathed to us today by the colonial-imperial modernity. This history requires a critical analysis of the way in which disciplinary divisions have been mapped onto anthropological types, as well as of the apparatus of area established on the basis of such multilayered mapping, and the role of translation, within that apparatus, as a subjective technology of antbropological figuration. 33 Closer investigation reveals that the hermeneutic circle of anthropological types that rotates through the apparatus of area is bylomorphic.

Simondon's critical understanding of the analogical relation, which rescues thought from its obsession with the topographical structure of objects, is complemented by his critique of species difference, which he conducts under the rubric of a sustained critique of hylomorphism. Hylomorphism refers to the assumption that the entities of the world can be perceived in series as the imposition of structural form upon pre-existent, passively unified matter. Hylomorphism is thus both an ontology and a taxonomy. The ascending schema of individual-species-genre defines the application of species logic to the social world of anthropological relations. The normalized form of this schema in the colonial-imperial modernity hinges on the pivotal role played by the nation-state between the individual and humanity. Yet it is not a schema that applies only to the internal relations among different populations within the larger set of global humanity, but rather applies equally to the relations that obtain between "humanity" and its two main others-animals and machines-during the First Epoch of Global Colonization. ${ }^{34}$ Just as Giorgio Agamben astutely observed in his reading of Linneaus, the colonial-imperial modernity defines "Man" precisely as

32. Bardin, 2015, p. 15 .

33. On the subjective technology of translation, Richard Calichman and John Namjun Kim, The Politics of Culture: Around the Work of Naoki Sakai, New York and London, Routledge, 2013.

34. I distinguish between two epochs of colonization: the first, typical of modernity, takes as its object territory and population and the products that result from interaction between the two; the second, typical of postmodernity, takes the entire biosphere and molecular life as its object. 
the being that is constantly trying to decide the boundaries of its species, both internally and externally. ${ }^{35}$ Agamben calls this programmatic aspect of "Man" a machine. Following Sakai's deconstruction of the normative national assumptions behind the modern regime of translation, we can see clearly how the regime of translation functions within the "anthropological machine": its task is to order human populations internally through the logic of species difference.

The value of Bardin's historical observations about the development of the disciplinary divisions of modern knowledge is properly speaking not historical but genealogical: it hinges upon our engagement with the present and the projection into the future. While inroads against an exclusively structuralist view were made in the humanities at the end of the $2 \mathrm{O}^{\text {th }}$ century, the World Trade Organizaiton's redefinition of higher education as a "service industry" has exercised an overwhelmingly mitigating effect on attempts to reorganize the disciplinary divisions of the humanities, inherited from the colonial-imperial modernity, in a way that would account for social phenomena from the point of view of relations rather than structures. From the perspective of the humanities, thus, contemporary restructuring has come to mean much more than just a series of adjustments in the institutional interface between capital and labour. In the circular dynamic unleashed between evaluation and valorization, humanistic knowledge production overwhelmingly returns to what Simondon terms structure through disciplinary divisions that favour pre-constituted objects. For the humanities, restructuring thus means the re-imposition of structure, rather than relations, as the primary point of engagement with knowledge.

To Bardin's history of structurally oriented disciplines, let us add now another historical perspective that draws from Franco Berardi's history of the refusal of work. ${ }^{36}$ Berardi narrates this history in relation to struggles for communication. His starting point is the moment when communication among workers, who had already been herded into the factory through dispossession, is interdicted by the disciplinary model applied throughout society to every single analogous space of enclosure (the factory, the school, the hospital, the family, the prison, etc.). But since it is a history of work in relation to communication, our starting point should really be placed at the moment prior to disciplinary interdiction, when the first need of the capital-state nexus was to create the communicational conditions that would enable dispossessed peasants from

35. Giorgio Agamben, The Open: Man and Animal, translated by Kevin Attel, Stanford, Stanford University Press, 2004, p. 26.

36. Franco Berardi, The Soul at Work: From Alienation to Autonomy. Francesca Cadel and Giuseppina Mechhia (tr.), with preface by Jason E. Smith, Los Angeles, Semiotexte, 2009. 
different regions to cooperate together in a single factory. The need to create a unified market, i.e., a market for labour, is paralleled by the need for a unified language. The creation of standardized language under the auspices of the nation-state, which always comes from the outside and above and is never an organic process from below, precedes, in a logical sense, disciplinary interdiction. Berardi's history moves into the $2 \mathrm{O}^{\text {th }}$ century explaining communism's promise and failure with regard to communication. The promise was that of concrete communication around the locus of erotic and inner wealth, while the failure was the reality of the totalitarian state, which applied with a vengeance the model of disciplinary interdiction. Finally, during the social movements and struggles of the 1960s and early 1970s, workers globally, rejecting the model of the Vanguard Party, figure out new and innovative ways to establish communicative relations beyond capture by capital. Hence, Berardi sees the adoption of information technologies into production beginning at the end of the I970s not as a sign of the inevitability of technological progress, but rather as an attempt by capital to respond to the workers' autonomy and exodus that gains momentum in the ig6os and i97os.

At a moment described as the "technological turn" 37 in translation studies, when questions of media, channel, and infrastructure are fast beginning to lead the field-a moment that ought properly to be seen as one facet of today's massive historical transition seemingly led by the integration of information technology, biotechnology, and nanotechnology within a framework of financialization and securitization-a counter history that combines the story of social speciation with that of disciplinary speciation could not be more urgent for rethinking translation's role in social relations and knowledge production. Translation is precisely one of those places where the polyvalent semantic field of the English word "species," covering economy, biology, and taxonomy (or disciplinary division) as a general principle of modern knowledge, is articulated.

We are reminded of Michel Serres' prescient observation in The Parasite, at the dawn of the age of information technologies, that "to communicate here is to calculate,

37. See Mary Snell-Hornby, The Turns of Translation Studies, Amsterdam and Philadelphia, John Benjamins, 2006; Minako O’Hagan, “The Impact of New Technologies on Translation Studies: A Technological Turn?" Carmen Millán and Francesca Batrina (eds.), The Routledge Handbook of Translation Studies, London and New York, Routledge, 2013, p. 503-517. 
that is to say, to encode. This universal can also be called money." ${ }_{38}$ While Serres' account calls attention to the link, the prototypical logistical model, between the economic and the linguistic, the gains are nevertheless limited. The logic of species difference, through which the economy of the universal is instituted, is recuperated in Serres' narration of the translational situation as a primordial gathering of nations, through which the "multitude" is formed. 39 A kind of "Mediterranean Myth" mobilized by the Romantic identification of people and language cripples Serres' concept of the multitude, severing the link to indeterminacy and hybridity-or better still, to potentiality, ordering it instead through the logic of species difference presently nationalized. At the dramatic moment when, in Serres' account, "[ $t]$ he translator comes forward," 40 it is simply according to a calculus of positions among languagenations networked within the logic of species difference. True, Serres does proceed to argue that the position primordially occupied by the translator is not a position per se, but rather a relation to relations. But the credibility of the argument is continually defeated by the text's constant reference to identities formed in the crucible of species difference: expressions such as "my tongue" and "the tradition" of "our own history," the "we" that are "like [but not individuating with] the Chinese," intersperse a text ponderously laden with classical references - the weight of the "Mediterranean Myth" that motivates the understanding of translation as civilizational transfer. Modernity is the story of Chinese becoming like us, or of becoming more like themselves, or of hopeless, bastard mixes based on the ontological priority of purity. This parallel configuration is not a simple Eurocentrism, unless we understand by that term the institution of a much broader phenomenon that characterizes the imperial-colonial modernity as a whole: the successive establishment of the apparatus of area as a key part of capitalist accumulation. Although my characterization of Serres is somewhat unfair, it is designed to call attention to the way in which the task of thinking, and breaking, the articulatory links within the polyvalent field of species difference remains unfinished for theoretical intervention today.

\section{LABOUR}

38. Michel Serres, The Parasite, translated by Lawrence Schehr, Baltimore and London, The Johns Hopkins University Press, 1982, p. 44.

39. Ibid., p. 40.

4o. Ibid., p. 42. 
There is a theoretical impasse in the constitution of translation studies, particularly visible in the institutionally configured mode of address hard-wired into area studies, found in the otherwise outmoded passage through Jakobsonian linguistics and Shannonian cybernetics. From the perspective of the history of disciplinary individuation that I have traced above, it is important to reflect on the meaning of the lag between communication studies, which have rejected Shannon's model, and area studies, which remain fundamentally invested in it. This disciplinary difference itself is key to understanding the distribution of heterogeneity managed by disciplinary divisions, seen as a whole, in the humanities. As suggested above, the primary reason for this difference among disciplines can be sought in the institutionalized forms of address that distinguish area studies from the normative humanistic sciences. The fact that knowledge production in area studies is always already implicated in a social relation to the population designated, and mediated, by the apparatus of area accounts for the reason why it has not experienced the "liberation" from Shannon's model that is now standard in a normative field such as communication studies.

It may help to illustrate, and hopefully open up, this crucial battlefield by highlighting the role of labour in the modern history of communication. One of the key tasks of this history is to avoid the pitfalls of abstraction and representation.

In talking about an operation, address, that is inaccessible to knowledge, it seems that we have run the risk of an abstraction that could potentially push the translational practice even further into that realm of metaphor from which we set out hoping to save it. One redress to this situation lies in taking seriously the phor, or act of carrying, in metaphor - taking it, in other words, more seriously and more concretely than a metaphorical idea would allow. Once we recognize the notion that code and message cannot be rigorously distinguished, ${ }^{41}$ the whole idea of signs as the bearers, or carriers, of originary meaning becomes untenable. Having thus dismissed the problem of transfer, we need to focus on what kind of act this is.

To the extent that this act is intrinsically productive, it is a form of labour. The concept of abstract labour, one of Marx's greatest theoretical discoveries, needs to be brought into contact with another great abstraction of the colonial-imperial modernity, the logistical reduction of communication. Cybernetics and linguistics have bequeathed understandings of the communicative situation that equate labour with the quantitative logic of productivity, and this deep-seated theoretical prejudice

4I. Jacques Derrida, Of Grammatology [1967], translated by Gayatri Chakravorty Spivak, Baltimore and London, The Johns Hopkins University Press, 1997, p. 29. 
has had enormous ramifications for our understanding of translation as a social practice. In Shannon's cybernetics, the transfer of messages is always configured in relation to the establishment of a channel. By its very nature as medium of transport, the channel is subject to interference, to what Shannon alternatively names "enemies" or "noise." ${ }^{42}$ In Jakobson's linguistics, the body is removed from speech events, enabling its abstraction into a semiotic event. As such, it is always only concerned with positions and the transferential relationship among them. This abstraction turns on the Jakobsonian distinction between indication and signification (precisely the point of intervention for Agamben's convincing demolition of the logic of species difference at the heart of modern linguistics). ${ }^{43}$ Symptomatically, visual perception is taken as the paradigmatic foundation for indication. An object illuminated by a spectrum visible to two or more interlocutors is pointed to. This is a version of visual perception that is reduced to a "physical" or objectivist account, one which falls apart as soon as the object at which one points or indicates is referenced by colour, which disrupts the neat dichotomies between subject and object. 44 When cybernetics reduces the labour of the translator and the undisciplined fecundity of the sign to the abstraction of noise, and then labels it an "enemy," an enormous step is being taken. The appropriation of social relations by the capitalist state begins with the idea that politics can be reduced to property, that property must be protected through the state's monopolization of violence, and that the activity of work must be chained to production. The dynamic is more extractive than productive. Information has to be extracted from communication just as wealth has to be extracted from social cooperation.

By contrast, in the translational situation elucidated by Sakai, we find that what cybernetics calls "the channel” cannot be distinguished from the translator any more

42. In Claude Shannon and Warren Weaver's The Mathematical Theory of Communication, [1949], Urbana and Chicago, University of Illinois Press, 1998, "noise” relates interference in the relation between sender and receiver. Taking up the same ideas in the context of classified work, titled "Communication Theory of Secrecy Systems," first circulated in 1946 and declassified in 1949, that would establish the foundations of cryptography, Shannon refers to the mediation, or interference, between source and destination as an "enemy cryptanalyst" instead of noise. Claude Elwood Shannon Collected Papers, N. J. A. Sloane and Aaron D. Wyner (eds.), New York, IEEE Press, 1993, p. 85 .

43. For an account of Agamben's critique of Jakobson and its relation both to translation and the apparatus of area, see Jon Solomon, "Invoking the West: Giorgio Agamben's 'Romantic Ideology' and the Civilizational Transfer," Concentric: Literary and Cultural Studies, vol. 40, $\mathrm{n}^{\mathrm{o}} 2$, 20I4, p. I25-I 47.

44. See Christophe Al-Saleh, Qu'est-ce qu'une couleur? Paris, Vrin, 2013. 
than the communicational transfer could be imagined apart from a moment of address, or relationality, as well. In the translational situation, the "noise" that inhabits the "channel" of translational "transfer" is precisely the labour of the translator, as well as the work of the sign. Yet just as the notion of abstract labour reduces the process of valorization to exchange value, the linguistico-cybernetic abstraction of the role of the translator reduces her role to that of a facilitator of transmission or exchange.

How are we then to understand the labour of the translator? Recent methodologies that emphasize the politics of translation bring sorely needed visibility to the translator's active role, but do little to help us understand the biopolitical aspects of translational work. "Biopolitics," Berardi reminds us, "represents a morphogenetic modeling of the living operated by the habitat with which it is required to interact." 45 The difficulty in approaching translation concerns the status of the "habitat." A biopolitics of translation focuses on the way in which translation is part of the "phase shift" in the metastable milieu in which translation occurs, and through which translational subjects are individuated. That milieu or "habitat" could never be reduced to the positivity of a code or the recognition of an identity. A significant part of the labour of translation occurs outside of the direct "product" of translational labour, in the mobilization of preindividual share (both langue and parole together). By contrast, the focus on identity at the heart of the politics (not biopolitics) of translation is unable to perceive the articulatory role of the nation-state in guaranteeing the cross-referenced index of species difference across the different domains of economy, biology, and general taxonomy or disciplinary divisions. In other words, the politics of recognition and representation cannot bring us all the way to understanding how translation functions as a subjective technology in the apparatus of area essential to capitalist regimes of extraction and accumulation.

It will not help us understand, for example, the subjectification engaged by the localization industry, which reportedly accounts for the bulk of translation jobs in today's market. ${ }^{46}$ The reduction of culture to metonymic codes is only the beginning. Localization is premised on the cybernetic emphasis on information rather than formation: the assumption that information is extractive by nature and that translation plays no role in the active, ongoing process of cultural individuation. The digital tools

45. Berardi, 2009, p. I87.

46. Mehmet Cem Odacioglu and Saban Kokturk, "From Inter-Disciplinarity to Trans Disciplinarity in the Academic Translation Teaching," International Journal of Comparative Literature ES Translation Studies, vol. 4, n², 2016, p. 4. 
upon which the industry relies enable even those who cannot speak or write foreign languages fluently to perform marketable translations. 47 Thus the translator-worker engaged by the localization industry could be doubly alienated from the work of translation, and translation becomes part of a larger system of social deskilling. Crucially, the sociality at stake concerns not only the relations among humans, but also the relations with entities assumed to be the "other" of the human, such as the information systems that form an increasingly important partner in the work of translation.

Combes reminds us that Simondon's concept of labour cannot be reduced to productivity. The first point of distinction concerns the excess of potentiality over production. There is a poietic dimension to labour beyond its role as praxis. The preindividual share from which every instance of individuation (i.e., the creation of entities) must draw can never be equated with the teleological end, or effective causal origin, of a generative process. The labour of the translator does not simply culminate in a product that we normally call "the translation." Nor is the translation itself, as Walter Benjamin sensed in his discussion of the "afterlife" of a work, a terminal point. The translation works on the so-called source and on the destination alike. And it also works upon what Sakai identifies as the essential hybridity of the translator. For this reason, we might say that the labour of translation is always an example of what Gregory Bateson calls "a double bind," a paradoxical form of communication that creates the terminal points between which it is supposed to form a bridge. The second point of divergence in the Simondonian concept of labour, which we now apply to translation via Sakai, and the category of productivity concerns the difference between work as deployment (of tools and machines in a logic of means and ends) and work as relating (i.e., individuation at a multiplicity of levels). In Combes' Simondon, or again in the Marx of today's theorists of primitive accumulation, labour is always an anthropological transformation. Alienation occurs precisely when the worker is socially deskilled. As we saw above with the example of the localization industry, technological upgrades and the skills required to manipulate them do not preclude simultaneous deskilling of labour's morphogenetic, social activity. These two differences that distinguish a Simondonian idea of labour from simple productivity coalesce in a single understanding of labour as both praxis and poiesis, production and creation. To understand translation in this way is to refuse to concede to a version of human nature (and transmediality) that is essentially prosthetic, always requiring the supplement of

47. Ibid. 
a tool and for that very reason perpetually exposed to-and cripplingly limited tothe dialectical choice between being either a master or a slave in the trade and traffic of species difference.

Now we can begin to appreciate the dimensions of the arena in which political and social struggle defined by translation occurs. Generally speaking, the labour of the translator has been vitally important to the modern articulation of species in all of its senses. As a result, the subjectivity of the translator must be, within the regime of accumulation, that of a labourer who does not know. And for a long time, it was indeed possible, through invisibility and socially-sanctioned gender roles, to prevent the translator from knowing. The operation of translation, as we saw above, cannot be identified per se. It takes the form of an event or a relation: the phasing of relations in language that occurs in the moment of address. Yet blinded to the operation, labour is reduced, according to Simondon, to a hylomorphic scheme "that imposes form on passive and indeterminate matter." ${ }^{8}$ As the labour of translation is alienated, it begins to work within and for the apparatus of area, turning linguistico-cultural potentiality into abstract labour for the economy of species difference. Technological prosthesis plays a greater and greater role. Today, the most valuable things that we can find in the old, human translation are its weaknesses: the propensity for failure and errancy, the stewardship of discontinuity in the social, and the access to transversal, indisciplined objects. Seen from the vantage point of translation, what communication reveals is not a situation of informational transfer nor the "code" that unconsciously "speaks" through language, but rather the discontinuity and disjointing that calls for translation in the first place. Yet influenced by cybernetics, translation studies in its area studies mode could only look at this disjunctive propensity in terms of lack. This was a form of fidelity that could only be judged by adherence to rules and structures. Object-love. But the true secret of translation is that of its potentiality, not lack or productivity.

Translation is a laboratory of individuation. Today, machines are being invited into this special laboratory. But instead of welcoming them as a partner in transindividuation - a mode of being that is not governed by species characteristicswe deskill ourselves and chain them to the productive economy. Under the dominance of logistics, capital now possesses a formidable capacity to communicate at speeds exponentially faster than social labour. If resistance in this situation seems futile, perhaps that is because our model of resistance still hinges on translation as a metaphor of structural transfer. The speed deficit means that the vector of access around which

48. Combes, 2013, p. 72 
affect becomes communicable is invariably fragmented. Our examination of nonassisted translation shows, however, that fragmentation and indeterminacy are essential elements of the translational situation. Yet it cannot be thought of simply as infrastructure. Or again, infrastructure must be thought of as an operation whose qualities include indeterminacy and potentiality. Hence, to view translation as an analogical experiment in morphogenetic transformation suggests a heterochronic field of intervention that does not have to rely on speed and productivity, or "infinite mobilization" 49 in linear fashion. I understand this to mean that the "very resistance of matter and time, medias and situations"so at the heart of transmedial theory's approach to labour cannot be understood as a cleavage between the material and the immaterial. As we have seen in the case of translation, cleavages hide the separation ${ }^{\text {SI }}$ between operation (address) and structure (communication). Separation is what sustains the possibility of the analogical jump that has, I hope, demonstrated its potential for an indisciplinary and non-colonial response to three types of divisions (labour, language, and knowledge) characteristic of modernity. As translation moves into a new, technologically-assisted realm, the originary hybridity of the translator and the indeterminacy of language(s) and people(s) will continue to serve as essential resources in the re-appropriation of relationships-transmediality—-from logistical species.

49. Peter Sloterdijk, La Mobilisation infinie : vers une critique de la cinétique politique, Hans Hildenbrand (tr.), Paris, Christian Bourgois éditeur, 2000.

50. Méchoulan, 2003, p. 27.

51 . Frédéric Neyrat and Elizabeth Johnson, "The Political Unconscious of the Anthropocene: A conversation with Frederic Neyrat by Elizabeth R. Johnson,” Society and Space, 20I4, https://societyandspace.com/material/interviews/neyrat-by-johnson/ (accessed May 20, 2016). 


\title{
Logistical Species and Translational Process: $A$ Critique of the Colonial-Imperial Modernity
}

\author{
Jon SOlOMON, UNIVERSITÉ JEAN MOULIN - LyON 3
}

\section{ABSTRACT}

This essay aims to sketch a theory of translation that would be of use in drawing links between three different types of divisions present in all modern societies: the disciplinary divisions within the institutional organization of scientific and humanistic knowledge; the geocultural/geopolitical divisions among global populations; and the economic divisions of labour, both in its external relation to capital and in the internal relations of different forms of labour to subjectivity. We propose that Naoki Sakai's theory of translation can be fruitfully compared to Gilbert Simondon's theory of transindividuation, and that the fruits from this comparison can be useful to develop an understanding of the analogical relationships between the three divisions cited above.

\section{RÉSUMÉ}

Cet article se propose d'esquisser une théorie de la traduction qui nous permettrait de comprendre les liens entre trois types de divisions actives au sein des sociétés modernes : les divisions disciplinaires des sciences humaines, les divisions géopolitiques et géoculturelles des populations mondiales et les divisions économiques du travail, à la fois dans sa relation externe avec le capital et dans le lien entre les différentes formes de travail et la subjectivité. En s'appuyant sur une comparaison entre la théorie de la traduction avancée par Naoki Sakai et la théorie de la transindividuation élaborée par Gilbert Simondon, nous proposons l'idée qu'il existe des relations de type analogique entre ces différentes divisions et que c'est la traduction qui detient la clé pour y accéder.

\section{BIOGRAPHICAL NOTE}

JoN Solomon is a professor at the Université Jean-Moulin in Lyon, France. He has lived in Asia for twenty-five years before arriving in France in 20Ir. For the past decade, he has been working on a project on the biopolitics of translation based on the theory of translation elaborated by Naoki Sakai. An author who writes principally in English and Chinese, he has also done numerous translations, including an emblematic Chinese translation of the essay "La communauté désœuvrée” by renowned French philosopher Jean-Luc Nancy (the title of the English translation of the same essay is “The Inoperative Community”). 